\title{
O fenômeno da ideologia e a criminalidade infantojuvenil
}

Cledna Dantas Lucena

Universidade do Estado do Rio Grande do Norte (UERN)

\section{O fenômeno da ideologia e a criminalidade infantojuvenil}

Resumo: Este artigo pretende contribuir para o debate a respeito das concepções ideológicas sobre a infância e juventude, e a inserção precoce desses sujeitos na criminalidade. Parte de pesquisas bibliográficas referente à temática, explanação das representações de ideias sobre a infância e juventude, a violência e exposição dos possíveis determinantes da inserção deste segmento no mundo do crime. É mister que haja uma desmistificação das ideias sobre os fenômenos da violência e da criminalidade infantojuvenil para que sejam explicitadas as reias condições de existência de crianças e adolescentes brasileiras.

Palavras-chave: Adolescentes. Ideologia. Criminalidade. Violência.

\section{The Phenomenon of Ideology and Children and Youth Criminality}

Abstract: This article contributes to the debate about ideological concepts about childhood and youth, and their precocious insertion in criminality. It conducts bibliographic research about the issue, and presents an explanation of the representation of ideas about childhood and youth, violence and of the possible determinants of their insertion in the world of crime. Ideas about violence and "criminality" of youth and children must be demystified to be able to explain the real living conditions of Brazilian youths and children. Keywords: Adolescents. Ideology. Criminality. Violence. 


\section{Introdução}

A sociedade capitalista, incapaz de promover o desenvolvimento social no mesmo patamar do econômico, engendra e aguça cada vez mais as desigualdades vivenciadas nocivamente pela população desprovida de propriedade e das condições mínimas de sobrevivência, expressas nas manifestações da questão social. Dentre estas, a questão da infância e juventude inseridas na "criminalidade" ganha uma superdimensão no meio social em desfavor dos fenômenos da violência e espoliação dos direitos deste segmento. O hiperdimensionamento dado à questão das crianças e adolescentes em conflito com a lei é possibilitado, de fato, por meio da disseminação de ideias de que esses sujeitos são os principais responsáveis pelo recrudescimento da violência e, portanto, pelo problema da insegurança na sociedade. Diante disso, há um forte clamor social por medidas repressivas a estes sujeitos que coíbam suas práticas e, ilusoriamente, solucionem o problema da segurança pública tão almejada pela população.

Nesse sentido, estamos, pois, diante do fenômeno da ideologia, ou seja, de concepções ideológicas a respeito da realidade social e da inserção da infância e juventude na "criminalidade". Resta-nos saber se estamos diante das reais condições materiais de existência destes sujeitos ou de representações de ideias sobre a infância e juventude no "mundo do crime".

\section{O papel da ideologia na sociedade capitalista}

O termo ideologia passa a ser apreendido como um conjunto de ideias de uma época determinada com o intuito de dar explicações aos elementos naturais e humanos de uma realidade e de sua conjuntura, precisamente, a representação de ideias sobre os fenômenos da sociedade e, não necessariamente, seus aspectos reais (Chaú, 2008). As ideias produzidas sobre a realidade e suas condições materiais não são representadas de forma autêntica e sim do modo imediato como elas aparecem na realidade. A tendência é, de acordo com essa visão, fazer uma representação invertida do processo real sem análise profunda, deixando ocultas a origem da produção e a reprodução das desigualdades.

A desigualdade social é engendrada pela dinâmica do modo de produção do capital, alicerçado na propriedade privada e na divisão social do trabalho como também na distribuição desigual dos produtos auferidos. Com o advento do sistema capitalista de produção, a divisão social do trabalho encontra seu ápice, constituída pelos proprietários dos meios de produção e os não proprietários - trabalhadores assalariados que dispõem somente de sua força de trabalho, tornada mercadoria e vendida aos capitalistas.

De acordo com Konder (2009), com a divisão social do trabalho tem-se a separação entre trabalho material e trabalho intelectual, que corresponde, respectivamente, aos trabalhadores que executam as tarefas e aos pensadores intelectuais que as pensam e as formulam. Portanto, é a partir daí que se tem a percepção de que as ideias não representam, de forma verídica, a realidade, porque são produzidas por teóricos, ou seja, pelos proprietários que estão separados da produção das condições materiais de existência. Desse modo, embora as ideias pareçam estar em contradição com a realidade, para muitos essas relações contraditórias permanecem ocultas, como algo separado e independente entre si. Nas palavras de Chaú (2008, p. 66), "as ideias aparecem como produzidas somente pelo pensamento, porque os seus pensadores estão distanciados da produção material". Contudo, essas ideias autonomizadas são ideias da classe dominante, tornadas independentes para que não sejam percebidas como suas e pareçam como dominação das ideias sobre os homens, ocultando a dominação do homem sobre o homem.

Segundo Konder (2009), é interesse dos capitalistas a manutenção das suas relações de dominação e, portanto, para lograr tal êxito, se valem da "elaboração de categorias lógicas e quadros interpretativos", a ideologia, que não levem a uma efetiva compreensão geral de sua verdadeira natureza. A ideologia se constitui como um instrumento de dominação de classe e tem como gênese a sociedade dividida em classes contraditórias. É relevante frisar, diante disso, que a luta de classes não se consubstancia somente no confronto armado, mas também por meio dos procedimentos institucionais, políticos, jurídicos, pedagógicos, dentre outros, que a classe dominante se vale para manter sua dominação e que os dominados utilizam para confrontar os dominantes. A classe dominante, além de explorar economicamente, necessita, para manter sua dominação, de dominar politicamente, utilizando dos procedimentos acima referidos, dispondo, portanto, de instrumentos para tal feito, por exemplo, o Estado e a ideologia.

O Estado, não obstante sua constituição ter como intuito a regulação da sociedade visando o interesse geral, configura-se majoritariamente como instrumento da classe dominante para a manutenção de seu poder. Esta dominação é exercida através dos aparelhos de repressão social do Estado com o fito de coibir as revoltas e manter a ordem social estabelecida. 
Segundo Chauí (2008), é através do Direito que o Estado aparece como legal, dispondo de leis para regular as relações sociais que favorecem os dominantes e devem ser obedecidas pelos dominados. Essas leis têm como propósito ocultar ou amenizar os aspectos da dominação, ou seja, ao invés desta ser vista como violenta, com o Direito, passa a ser legítima e, respectivamente, não violenta e aceita por todos. Se a classe dominada percebesse o Estado e o Direito como instrumentos de violência consentida, estes não seriam respeitados e os dominados se revoltariam. É, nesse contexto, que se introjeta a ideologia para impedir que essa violência e dominação sejam percebidas e que as leis pareçam legítimas: "A função da ideologia consiste em impedir essa revolta fazendo com que o legal pareça para os homens como legítimo, isto é, como justo e bom. Assim, a ideologia substitui a realidade do Estado, pela ideia do Estado - ou seja - a dominação de uma classe é substituída pela ideia de interesse geral encarnado pelo Estado" (CHAUİ, 2008, p. 86-87).

Assim, é perceptível que quem domina a produção material, social e política também deve ser dominante no plano ideológico, tornando a maneira de representar sua classe a forma como toda a sociedade irá pensar. Parafraseando Marx e Engels (2009, p. 67), "as ideias da classe dominante, são em cada época, as ideias dominantes".

É válido ressaltar que, para a ideologia realizar sua função de servir a classe dominante como instrumento de dominação desta, necessário se faz que as ideias da classe dominante sejam transformadas em ideia universais. Segundo Chaú́ (2008), a representação da realidade é feita de forma abstrata e invertida para que pareça real. Ou seja, a ideologia ao representar as ideias da classe dominante como universais, como um modo de vida bom e justo para todos, cumpre sua tarefa de ocultar a dominação e exploração dos dominantes sobre os dominados, bem como a origem da produção e reprodução da desigualdade social.

Para que a ideologia consiga objetivar os aspectos supramencionados, tem como pressuposto a alienação. Esta é concebida como o estranhamento do homem com relação à produção das suas condições materiais de existência para que estas não pareçam como produzidas por este e sim por outrem, como por exemplo, uma entidade, um Deus que define sua vida, a forma social em que vive, devendo se submeter ao que foi dado e criado pelo outro. A alienação, na sociedade capitalista, consubstancia-se com aspectos da reificação, a coisificação do humano, em que transforma as relações sociais em ações mercadológicas, conforme expresso por Konder (2009, p. 132), "com o esmagamento das qualidades humanas e individuais do trabalhador por um mecanismo inumano, que transforma tudo em mercadoria".

Diante disso, ainda que os sujeitos percebessem, em certa medida, que estão inseridos em relação de desigualdade, a ideologia, indissociável da alienação, produz ideias para que os sujeitos creiam que são desiguais por natureza, aceitando sua condição e submetendo-se a ela, e, consequentemente, naturalizando as desigualdades e ou não percebendo os determinantes que a produzem e a reproduzem. À medida que cresce a capacidade de ocultação da origem das desigualdades, ou seja, da contradição e dos conflitos de classe, aumenta o poder da ideologia de representar os interesses de quem a domina. Assim, na sociedade capitalista, as ideias da classe dominante são criadas para servir a seus interesses, isto é, a ideologia cumpre o papel de manter seu poder e dominação. Exemplificando, a ideologia burguesa cria representações sobre famílias concatenadas a seus interesses. De acordo com Chauí (2008, p.84), a família é concebida, na sociedade burguesa, como sagrada, moral, pedagógica, e não como sua real configuração, com formas, funções e sentidos diferentes: "estamos, pois, diante da ideia de família e não da realidade histórico-social da família".

É, diante dessa perspectiva que se pretende desvelar alguns determinantes da inserção de crianças e adolescentes na "criminalidade", bem como analisar a questão da espoliação de direitos deste segmento, desmistificando, assim, as representações de ideias como: sujeitos de de alta periculosidade, sujeitos responsáveis pelo aumento da criminalidade e violência, dentre outras representações.

\section{Adolescentes em conflito com a lei e as concepções ideológicas}

\subsection{Determinantes da criminalidade infantojuvenil e a ideologia da violência}

A questão da inserção precoce da infância e juventude brasileiras na "criminalidade" tem suscitado uma agitação social da população em busca de soluções, por parte do Poder Público, que coíbam essa prática e restabeleça a segurança pública, preferencialmente, com a intensificação de medidas repressivas a estes sujeitos.

O modelo de sociedade capitalista, consubstanciado na contradição de interesses entre as classes e, portanto, engendrador das desigualdades sociais, acarretando, ainda, no descalabro da desigual distribuição de renda, favorece uma minoria e desfavorece a maior pate da população - trabalhadora - que vivencia, nocivamente, diversas expressões da questão social, dentre estas, cabe ressaltar a situação de crianças e adolescentes inseridos no "mundo do crime". 
Com o fito de contribuir com a discussão, é relevante expor a concepção sobre a relação entre consumismo e criminalidade descrita por Costa (2005) que afirma pertencermos a uma sociedade consumista e, portanto, tudo que é realizado tem como objetivo último o consumo, não importando, para algumas pessoas, os meios para atingi-lo. E, no ordenamento vigente, para concretizar o desejo de consumir, é preciso que se obtenha um determinado poder aquisitivo para se inserir como um cidadão consumidor. Porém, o ínfimo - ou até inexistente - salário da população subalterna restringe seu poder de compra, excluindo-a do seleto grupo de cidadãos consumidores. O consumismo constitui-se como um dos motores de reprodução do capitalismo, visto que as mercadorias produzidas precisam ser vendidas para a manutenção do ciclo reprodutivo do capital e expansão de seus superlucros. Para isso, há exorbitantes campanhas de mídia com o intuito de persuadir a população ao consumismo. Nesse contexto, a sociedade consumista, cindida entre os que podem consumir e os destituídos de poder aquisitivo para o consumo devido às condições de vulnerabilidade social, aumenta e expõe o hiato existente na estrutura social pelos cidadãos consumidores e os indivíduos sem cidadania.

Esses fatores, somados às deficiências dos serviços públicos e ao retrocesso de direitos, põem em evidência os privilégios da classe dominante, detentora de poder aquisitivo tanto para o consumo das mercadorias do mercado convencional, como para consumir os serviços tornados mercadorias que não são ofertados de forma eficiente pelas instituições públicas. Aos sujeitos da classe dominada restam-lhes o infortúnio e a conformação das suas condições de vida degradantes, pois, os que possuem algum rendimento, mal conseguem ultrapassar os limites da subsistência, quiçá satisfazer seus desejos e renderem-se à sedução dos mercados.

Nessa perspectiva, a criminalidade não deve ser concebida como produto do mau funcionamento da sociedade ou de fatores externos a mesma. Nas palavras de Costa (2005, p. 67), a criminalidade "é o próprio produto inevitável da sociedade de consumidores". Afirma ainda que: "O padrão estabelecido de consumo é o fim a ser alcançado, como uma tarefa individual, para a qual não existem regras específicas regulamentadas. Assim, os fins justificam os meios e ampliam-se o espaço para a criminalidade crescente". A tendência é o crescimento da criminalidade, uma vez que esta é produzida e reproduzida pela dinâmica do sistema capitalista que gera a necessidade do consumo sem proporcionar as condições de sua efetivação para a maioria da população expropriada de poder aquisitivo.

Portanto, essa propensão referida, também recai sobre as crianças e adolescentes que se aventuram nas ilusórias facilidades no mundo de crime, em busca de satisfazer suas necessidades e inserirem-se como cidadãos consumidores. Este fator é concebido como um dos determinantes da inserção desses sujeitos na "criminalidade". Nessa linha de raciocínio, a ordem do capital engendra as desigualdades entre as classes excluindo dos benefícios socioeconômicos a população subalterna que terá que "se virar" para se tornar um cidadão-consumidor. Trata-se de um sistema que gera suas próprias crises e, consequentemente, suscita as revoltas num "salve-se quem puder", sob pena de sucumbir, mais precisamente, um modelo de ordenamento social que gera a desordem expressa nas inúmeras refrações da questão social, dentre estas, a violência e a criminalidade.

Nesse sentido, é válido expor também como um dos determinantes da inserção de adolescentes na "criminalidade" - intrinsecamente ligado a apologia do consumo - as condições subumanas de existência da infância e juventude que impactam, de forma nefasta, o desenvolvimento pleno desses sujeitos. As situações de violência e violações de direitos expropriam tanto a sua cidadania e dignidade, como também qualquer expectativa de melhoria de vida. Destituídos de projeto de futuro, restam-lhes a reprodução imediata da vida cotidiana que os impelem a buscar, por seus próprios meios, alternativas de sobrevivência não encontradas nas instituições adjacentes, como a família, a comunidade, e o Estado, porém, disponibilizadas nas ilusórias facilidades do "mundo do crime". Segundo Rosa (2001, p. 183), "para estes, o projeto de vida parte da necessidade, ou da carência de oportunidades, restando-lhes a inserção social no imediato, ou seja, trabalhando, roubando, pedindo, brincado".

Portanto, seguindo essa linha de raciocínio, esses sujeitos se inserem na "criminalidade" com o intuito de obter tanto os produtos para a mera sobrevivência, como também os atrativos objetos de consumo do mercado. Com isso, logo são associados à violência como os principais responsáveis por sua produção e reprodução. Dessa forma, são tidos como o mal da sociedade, como protagonistas da intensificação da violência.

Todavia, a associação desses sujeitos à violência não encontra respaldo na realidade, pois sua produção/ reprodução é engendrada pela dinâmica do sistema capitalista. Soma-se a isso, a violência advinda de outras esferas da sociedade como a família, as instituições e o Estado, que, de forma recorrente, recai sobre as crianças e adolescentes:

O crime é a face mais descarada da violência. Acaba se constituindo numa cortina de fumaças, desviando a atenção da opinião pública de suas determinações. Por exemplo, uma criança ou adolescente trabalhando como cortador de cana na zona rural não é visto como objeto de violência, afinal, é melhor trabalhar do que assaltar! (me assaltar). O trabalho precoce das crianças é apenas uma face da "naturalização da violência" neste complexo tecido social (ROSA, 2001, p. 183). 
Nesses termos, de acordo com Chauí (2008), estamos, pois, diante de representações ideológicas sobre a violência, uma vez que esta não nos é apresentada em suas diversas facetas, ocultando o sistema responsável por sua reprodução e, consequentemente, culpabilizando os adolescentes em conflito com a lei como seus principais reprodutores. Há uma disseminação no meio social de ideias de que a maior parte dos crimes são cometidos por adolescentes, porém, os dados da Secretaria Nacional de Segurança Pública, de 2014, desmistificam essa ideia revelando que, dos crimes praticados no Brasil, somente $0,01 \%$ são atos infracionais cometidos por estes e dos atos infracionais graves, cometidos com violência, como homícidio, latrocínio e estupro, apenas $0,05 \%$ tem como autores os(as) adolescentes, desvelando o mito da alta periculosidade desses sujeitos.

Há, portanto, de acordo com Chauí (2008), uma inversão da realidade para que os determinantes da violência sejam desfocados de seu real produtor e reprodutor - o sistema capitalista -, recaindo a culpa sobre os adolescentes em conflito com a lei, que, apesar de estarem inseridos em situações de violência, estas são naturalizadas e ou invisibilizadas. Em contraponto, uma parte da sociedade superdimensionam as violências praticadas por estes e propõe, como solução mágica para o problema da insegurança social, a intensificação da repressão.

\subsection{De vítimas a vitimizadores: a invisibilidade da escassa cidadania e a visibilidade da violência}

A sociedade brasileira, apesar de atingir, a nível econômico, o patamar de sétima economia mais rica do mundo ocidental, não foi capaz de produzir os mesmos avanços na esfera social. Essa realidade é refletida nas condições materiais de existência da população, resultantes do processo de acumulação capitalista e da concentração dos produtos auferidos, acarretando no aguçamento das desigualdades sociais. Esta situação é vivenciada pelas crianças e adolescentes que, além de sofrerem com as condições de miséria e espoliação de direitos, ainda são vítimas de violências praticadas pela família, Estado e sociedade, por exemplo, maus-tratos, abandono, abuso sexual, prostituição, trabalho infantil, extermínio, desnutrição, dentre outras. No entanto, essas e outras violências não são visibilizadas, ao menos, da forma que deveriam, pois, não há, diante dessas situações, a mesma ou parecida repercussão social que existe sobre a prática de ato infracional, como também esses sujeitos não recebem o devido tratamento e proteção garantidos.

Não obstante os avanços na legislação infantojuvenil, com a introdução de uma ampla gama de direitos do Estatuto da Criança e do Adolescente (ECA), a infância e a juventude brasileiras ainda são, majoritariamente, submetidos às situações de violências acima referidas, retratada na escassez de cidadania. Ao tentarem se incluir no mercado como cidadãos consumidores, mediante a prática de atos infracionais, logo ganham visibilidade. Contudo, enquanto permanecem como vítimas que sofrem violências, obtêm ínfima relevância para a sociedade, mas quando passam a praticá-las tornam-se o centro das atenções e das preocupações no meio social, geralmente de forma pejorativa, visto que a preocupação está voltada primordialmente para a segurança pública. Segundo Silva (2005, p. 34), "apesar de viverem uma história em que são violentados, são as violências produzidas por eles que ganham visibilidade na sociedade, na medida em que a mídia mostra com prioridade situações de violência e de insubordinação". Ao se aventurarem no "mundo do crime" passam da condição de vítimas - até então invisíveis para a sociedade -, a vitimizadores, ganhando, portanto, visibilidade social. Essa situação é retratada por Sales (2007) como crianças e adolescentes em situação de "invisibilidade perversa" por não possuírem um lugar digno nesta sociedade, uma vez que sobrevivem da desordem, das escórias do sistema, e, quando tentam romper com essas condições de violências, transgredindo as normas, passam do estado de "invisibilidade perversa" para o de "visibilidade perversa" como metáforas da violência. Esse quadro corrobora para a ampliação das medidas repressoras do Estado à infância e juventude e, consequentemente, para a intensificação da violação de direitos deste segmento, visto que as situações de violências de que são vítimas, são banalizadas, naturalizadas pelo Estado e pela sociedade. Há, portanto, uma nítida tendência de superdimensionamento dos crimes praticados pela juventude numa clara inversão de prioridades, tornando irrelevante o problema da escassez de cidadania destes sujeitos, como também a proteção e garantia de seus direitos.

\section{A ideologia da segurança e as medidas repressivas de contraponto ao ECA}

O Estatuto da Criança e do Adolescente introduz um novo paradigma de tratamento a esses sujeitos que, balizado na Doutrina da Proteção Integral, tem como objetivo a proteção especial para este segmento. Para o ECA, crianças e a adolescentes devem ser prioridades absoluta, e, concebidos como sujeitos de direitos, devem receber uma política especial de atendimento condizente com sua concepção de "pessoas em condição peculiar de desenvolvimento". Soma-se a isso, o disposto no ECA de que é dever da família, do Estado e da sociedade em geral, colocá-los a salvo de qualquer forma de violência, crueldade, negligência e de opressão. 
Cabe enfatizar que os direitos devem ser implementados pelo Estado mediante políticas públicas com a colaboração da família e da sociedade. Especificamente, com relação às crianças e adolescentes em conflito com a lei, serão destinadas medidas protetivas àquelas, e, a estas, as medidas de proteção e as socioeducativas. Para tanto, deve contar com uma rede de apoio articulada entre as esferas da assistência, justiça, saúde, educação, dentre outras, objetivando tanto a proteção de seus diretos como também a ressocialização. A esse respeito, embora o ECA tenha inovado com as medidas socioeducativas visando à reeducação, à garantia e proteção dos direitos deste segmento, ainda há, demasiadamente forte, um clamor social por medidas mais severas a estes sujeitos, inclusive, com a proposta do rebaixamento da idade de inimputabilidade.

É pertinente expor que há majoritariamente a implementação de medidas repressivas por parte do Estado embasadas pela ideologia da segurança e paz social. Conforme expresso por Costa (2005, p. 71), "ganha espaço o discurso justificador do uso da violência por parte do Estado, como forma de garantir a segurança da população". Apesar de a violência ser engendrada pela dinâmica do sistema capitalista, a responsabilização recai sobre a população oprimida, alvo das penalizações do Estado que culpabiliza o indivíduo taxando-o de anormal por não conseguir viver harmoniosamente na sociedade, ameaçando, constantemente, à ordem social estabelecida.

\section{Ao tentarem se incluir no}

\section{mercado como cidadãos}

consumidores, mediante a

prática de atos infracionais,

logo ganham visibilidade.

Contudo, enquanto

permanecem como vítimas que

sofrem violências, obtêm

ínfima relevância para a

sociedade, mas quando passam

a praticá-las tornam-se o

centro das atenções e das

preocupações no meio social, geralmente de forma

pejorativa, visto que a

preocupação está voltada

primordialmente para a

segurança pública.

Diante do exposto, dissemina-se a ideia de que os adolescentes em conflito com a lei são os principais engendradores da violência e, portanto, da insegurança social. Assim, deve ser dispensado, a estes, medidas repressivas/coercitivas em benefício da ordem social. Todavia, trata-se, na verdade, de práticas de controle e limpeza social, mistificada pela ideologia da segurança pública. Vale ressaltar, que estamos diante do mito de que o problema da segurança pública seria resolvido através da solução mágica do combate ao crime infantojuvenil, de forma repressiva, a despeito das medidas socioeducativas e demais políticas. Segundo Costa (2008, p. 72), "trata-se da ilusão ou crença na sociedade isenta de conflitos, na qual os criminosos são identificados como o mal que precisa ser combatido, intimidado por meio de uma política criminal ostensiva e intolerante". Cabe explicitar, ainda, a propagação da ideia de que, ao culpabilizar esses sujeitos pelo recrudescimento da violência e criminalidade, a redução da idade penal constituiria como solução eficaz ao problema da segurança pública. Nas palavras de Saraiva (2008, p. 157), "alguns setores dão tanta ênfase a esta proposta que induzem a opinião pública a crer que seria a solução mágica na problemática da segurança pública, capaz de devolver a paz tão almejada por todos".

Desse modo, estamos diante de representações ideológicas sobre a segurança pública segundo a qual esta não propiciaria aos sujeitos da classe subalterna seu pleno usufruto. Isso porque as ideias propagadas resultariam em mais repressão e isolamento deste segmento da sociedade. $\mathrm{Ou}$ seja, acarretariam uma limpeza social para reprimir e controlar/dominar a população desordenada que, além de não solucionar o referido problema, oculta a realidade, deixando intactas as raízes da violência, numa clara consonância com os interesses dos dominantes para manter o poder e a dominação sobre os oprimidos. De acordo com a afirmação de Chauí (2008, p. 78), "a ideologia ao representar as ideias daclasse dominante como universais, cumpre sua tarefa de ocultar a exploração dos dominantes sobre os dominados".

Nessa perspectiva, há uma inversão da realidade que, através das concepções ideológicas, oculta os determinantes da violência e naturaliza as desigualdades como, por exemplo, a associação dos adolescentes às violências. Parafraseando Sales (2007), "adolescentes infratores são como metáforas da violência" numa falsa relação entre população pauperizada e "classe perigosa" de onde provêm os maus elementos constituindo-se, assim, na criminalização da pobreza como uma cortina de fumaças, desviando a atenção da opinião pública das inúmeras facetas da violência e suas determinações. 
O quadro de soluções apresentado para o combate à "criminalidade" juvenil consubstancia-se, sobretudo, com práticas repressivas a despeito do caráter socioeducativo da legislação infantojuvenil. Com isso, tornase clara a pretensão do Estado de controle social e manutenção da ordem em detrimento da implementação de políticas públicas universais de acesso aos bens de consumo para a coletividade deixando, assim, sob controle a população desordenada. Segundo Costa (2005, p. 74): “Antes de oferecer políticas sociais, se gastam com a aparatos repressivos, não porque sejam mais caros ou mais baratos, mas porque são mais eficazes do ponto de vista higienista. A culpabilização individual faz com que não reste alternativa senão a de terminar com aqueles que provam ser incapazes de pertencer à sociedade de consumo"

Esse contexto mostra a difícil coexistência entre os direitos positivados no ECA e sua materialização na realidade. Para Chauí (2008), as leis tem como objetivo ocultar ou amenizar os aspectos da desigualdade e dominação. Há uma incongruência entre as ideias de prioridade absoluta, proteção integral e sujeitos de direitos do ECA e a realidade das condições de existência deste segmento. Trata-se, pois, de representações de ideias da infância e juventude e não da realidade histórico-social destes sujeitos, visto que são destituídos de direitos e alvos de repressão e violências.

\section{Considerações finais}

Há uma contradição entre as ideias sobre a infância e juventude e as condições reais de existência deste segmento que precisam ser desmistificadas com o fito de propiciar o desvelamento da realidade de milhões de crianças e adolescentes desprotegidas pela família, Estado e sociedade, espoliadas de seus direitos devido à vivência em condições vulneráveis e de risco social. Assim, necessário se faz que haja uma desmistificação das concepções ideológicas com relação a associação destes sujeitos ao recrudescimento da criminalidade e violência. Para isso, as suas reais e vulneráveis condições de existência devem ser enfatizadas, expondo a sua predominante condição de vítimas, conforme revela o mapa da violência (2014): dos homicídios ocorridos no Brasil, em 2012, 53\% das vítimas eram jovens entre 15 e 29 anos, configurando-se num dado alarmante de extermínio da juventude brasileira, desmascarando o superdimensionamento dado às ações de vitimização como, por exemplo, o falso discurso de engendradores da violência. Há, na realidade social, uma restrição de direitos destes sujeitos e, consequentemente, um retrocesso das conquistas dos movimentos sociais e demais propugnadores deste segmento referente ao paradigma de proteção integral e da ampliação de direitos do ECA. Nesse sentido, é urgente a revitalização das lutas em prol da garantia e, sobretudo, materialização do ECA, bem como a não permissão de medidas de cunho repressivo/coercitivo. Ou seja, sob pena de mais retrocessos, há a necessidade de lutar por ampliação de políticas públicas universais para a infância e juventude.

É relevante e imprescindível, portanto, que, apesar das dificuldades de se obter a plenitude de direitos nos marcos do capitalismo, lutemos pelo máximo de ampliação da cidadania e proteção destes sujeitos. Somente quando possuirmos amplas políticas garantidoras e materializadoras dos princípios preconizados no ECA é que poderemos reverter o quadro de violência e "criminalidade" de que são vítimas e vitimizadores a infância e juventude brasileiras. Essa perspectiva pretende garantir a este segmento os direitos imprescindíveis ao seu desenvolvimento pleno em condições de liberdade e dignidade.

\section{Referências}

BRASIL. Estatuto da Criança e do Adolescente. Lei no 8.069/90, de 13 de julho de 1990. . Secretaria Nacional de Segurança Pública. Ministério da Justiça. Disponível em: <http://portal.mj.gov.br/data/Pages/MJ1C5 BF609PTBRNN.htm>. Acesso em: jun. 2015.

CHAUÍ, M. O que é ideologia? São Paulo: Brasiliense, 2008.

COSTA, A. P. M. Adolescência, violência e sociedade punitiva. In: Serviço Social e Sociedade. N. 83. São Paulo: Cortez, 2005. KONDER, L. Marxismo e Alienação. São Paulo, Expressão Popular, 2009.

MARX, K.; ENGELS, F. A ideologia Alemã. São Paulo: Expressão Popular, 2009.

ROSA, E. T. S. Adolescente com prática de ato infracional: a questão da imputabilidade penal. In: Serviço social e Sociedade. São Paulo: Cortez Editora, n. 67, 2001.

SALES, M. A. (In)visibilidade perversa: adolescentes infratores como metáfora da violência. São Paulo: Cortez Editora, 2007.

SILVA, M. L. de O. O Estatuto ds criança e do adolescente e o Código de Menores: descontinuidades e continuidades. In: Serviço Social e Sociedade. São Paulo: Cortez, n. 83, 2005.

VOLPI, M.; SARAIVA, J. B.; KOERNER, R. (org). Adolescentes privados de liberdade - A normativa nacional e internacional \& Reflexões acerca da responsabilidade penal. São Paulo: Cortez, 2008. 


\section{Nota}

1 Os termos criminalidade e mundo do crime aparecerão, em alguns momentos, entre aspas para corroborar o preconizado pelo Estatuto da Criança e do Adolescente de que estes sujeitos não praticam crimes e sim atos infracionais. Assim, sempre que referir a esses termos, as aspas servirão para informar que, apesar de estarem praticando atos infracionais análogos aos crimes, não são considerados criminosos e sim autores de ato infracional.

\section{Cledna Dantas Lucena}

clednadl@ hotmail.com

Assistente Social, mestre em Serviço Social e Direitos Sociais pela Faculdade de Serviço Social da Universidade do Estado do Rio Grande do Norte (UERN)

\section{UERN}

Rua Almino Afonso, 478 - Centro

Mossoró- Rio Grande do Norte - Brasil

CEP: $59.610-210$ 